\title{
Dynamic Coupling of Computational Fluid Dynamics and Thermodynamics Software: Applied on a Top Blown Converter
}

\author{
Mikael ERSSON, Lars HÖGLUND, Anders TILLIANDER, Lage JONSSON and Pär JÖNSSON \\ Division of Applied Process Metallurgy, Royal Institute of Technology (KTH), SE-100 44 Stockholm, Sweden.
}

(Received on November 8, 2007; accepted on December 10, 2007)

\begin{abstract}
A novel modeling approach is presented where a computational fluid dynamics software is coupled to thermodynamic databases to obtain dynamic simulations of metallurgical process phenomena. The modeling approach has been used on a fundamental model of a top-blown converter. Reactions between gas-steel, gas-slag, steel-slag and gas-steel-slag have been considered. The results show that the mass transport in the surface area is totally controlled by convection. Also, that a large amount of CO produced during the decarburization might slow down the rate of decarburization in droplets ejected from the bath. For the present simulation conditions reflecting laboratory experiments, it was also seen that the amount of slag $\left(\mathrm{FeO}\right.$ and/or $\left.\mathrm{SiO}_{2}\right)$ created is close to zero, i.e. only gas $\left(\mathrm{CO}+\mathrm{CO}_{2}\right)$ is created as the oxygen jet hits the steel bath. It was also illustrated how an extrapolation of the decarburization rate, sampled from a few seconds of simulation, could be done to get a rough estimate of the carbon content at a later stage in the process as long as the carbon content is relatively high. The overall conclusion is that it is possible to make a dynamic coupling of the Thermo-Calc databases and a CFD software to make dynamic simulations of metallurgical processes such as a top-blown converter.
\end{abstract}

KEY WORDS: BOF; CFD; thermodynamics; modeling; slag and dynamic simulations.

\section{Introduction}

In many metallurgical processes involving an oxygen-jet impinging onto a steel bath surface, a good understanding of the underlying fluid dynamics is desirable in order to optimize the involved kinetics such as decarburization. There have been several experimental reports on the subject for instance $^{1-7)}$ and also some numerical or Computational Fluid Dynamics (CFD) reports. ${ }^{8-13)}$ Szekely and Asai ${ }^{8)}$ presented a computational model of a jet impinging onto a liquid surface. Ngyen and Evans investigated the effect the nozzle-to-pool diameter ratio had on the deformation of the liquid surface caused by an impinging jet, using a computational model. ${ }^{9)}$ Zhang et al. modeled a combined blown case where a top jet as well as a submerged jet was employed. ${ }^{10)}$ Odenthal et al. showed a multiphase CFD model of a top blown converter where splashing phenomena due to the impinging jet was investigated as well as the mixing time in the converter due to bottom and top blowing. ${ }^{11}$ Nakazono et al. described a two-phase numerical analysis of a supersonic $\mathrm{O}_{2}$-jet impinging on a liquid iron surface containing carbon. ${ }^{12)}$ The calculations were performed under vacuum and addressed surface chemistry between the gas- and the steel-phase. The model used a steady state approach without treatment of splashing, ripples etc. There are also other non top blowing CFD models presented in the literature that address chemical reactions in metallurgical systems, see for instance. ${ }^{14,15)}$ Jonsson et al. presented a coupled CFD and thermodynamics model of sulfur refining in a gas-stirred ladle. ${ }^{14)}$ The thermodynamics was incorporated in the CFD program as a custom subroutine specifically written for the investigated system. A schematic of such an approach can be seen in Fig. 1.

Recently a CFD model consisting of a top blown system has been presented and compared to experimental data. ${ }^{13)}$ Here an extension to this model is presented which includes reactions i.e. a gas/liquid/slag Volume of Fluid (VOF) ${ }^{17)}$ multiphase model, for a top blown system. Reactions between all phases have been allowed as well as expansion/ contraction associated with the creation or destruction of phases in the computational cells. The methodology of the setup is shown and finally some illustrative results of a fundamental top blown converter model are presented.

\section{Numerical Model}

The current modeling approach is seen in Fig. 2. It is built in a modular fashion in order to ease the incorporation of new research into the model. This also means that very little reprogramming is necessary when changing from one system to another, as long as the thermodynamic data is present in the thermodynamic database and the capabilities of the CFD software is not exceeded.

The simulations have been performed on a Linux PC cluster containing 6 nodes. The real-life simulation time has been highly dependent on the number of Thermo-Calc calls performed so no typical simulation time can be given; it varies between one hour and ten days real-time for a $10 \mathrm{~s}$ 


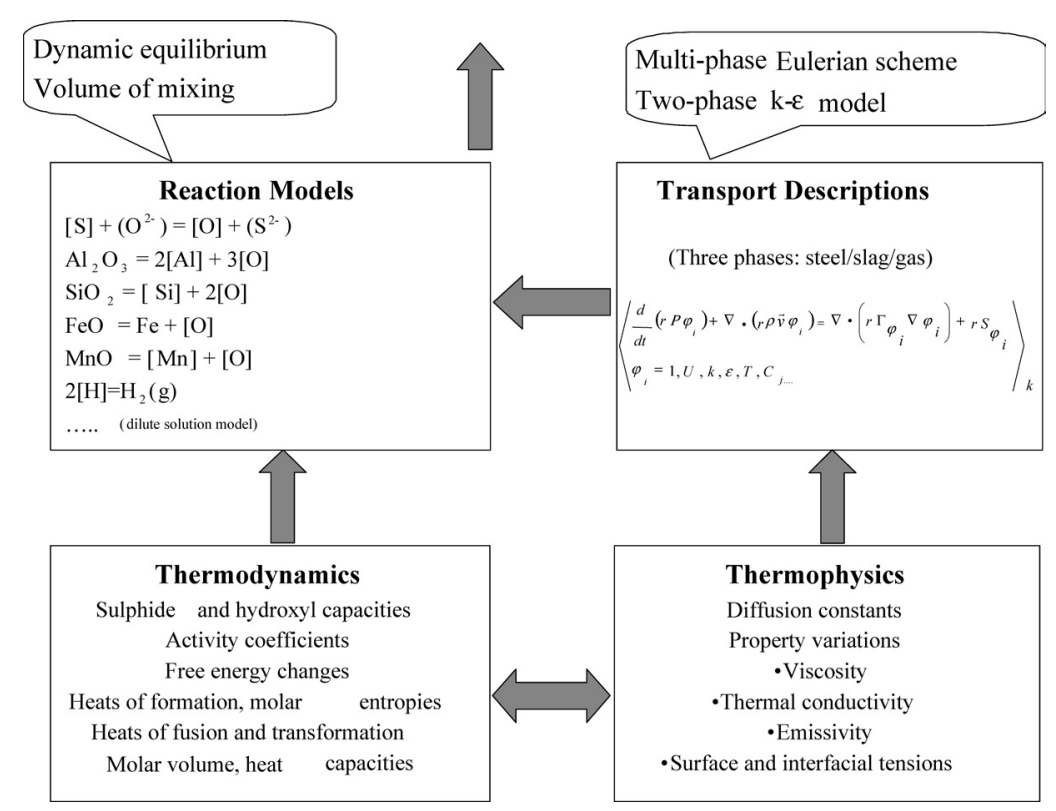

Fig. 1. Schematic of a numerical model approach with combined CFD and thermodynamics modeling. From Ref. 14).

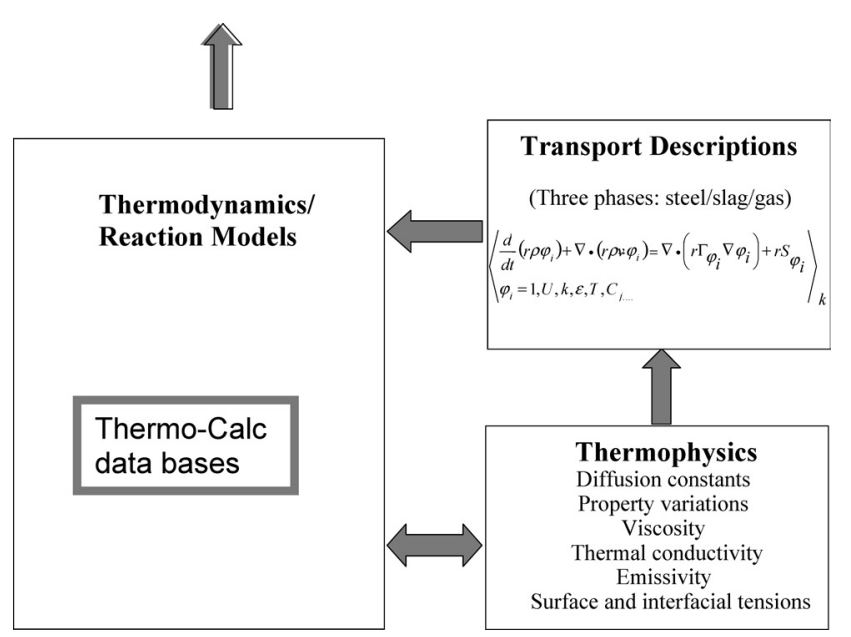

Fig. 2. Schematic of a numerical model approach with combined CFD and thermodynamics modeling. Modular approach that uses databases from the Thermo-Calc software.

simulation. In Fig. 3 a schematic of the physical and numerical domains can be seen. The boundary conditions used are velocity inlet, pressure outlet, no-slip walls and symmetry axis. Standard wall functions have been used for both walls. ${ }^{18,19)}$ The realizable $k-\varepsilon$ model $^{20)}$ has been used in all examples. The domain width is $0.075 \mathrm{~m}$ and the height is $0.13 \mathrm{~m}$. Initially, a $15.6 \mathrm{~kg}$ steel-melt is introduced with a temperature of $1500^{\circ} \mathrm{C}$. From the top lance, placed $0.01 \mathrm{~m}$ above the steel, a mass flow inlet was specified corresponding to a volumetric flow rate of $25 \mathrm{~L} / \mathrm{min}$ of pure oxygen. In Table 1 various parameters used in the simulation can be seen and in Table 2 the initial concentrations of the different species are shown.

\subsection{CFD}

The Ansys Fluent software has been used which is a commercial finite volume solver used for computational fluid dynamics. ${ }^{19)}$ Conservation equations of mass, momentum, energy and species are solved. Depending on the turbulence model used some extra conservation equations are

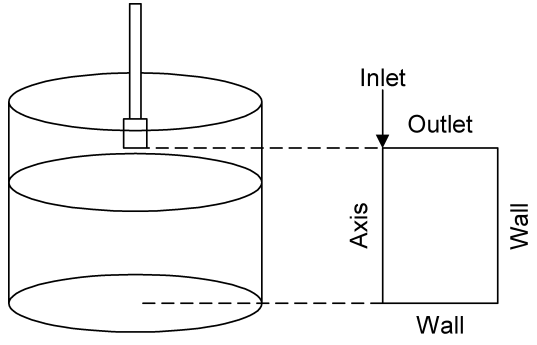

a)

b)

Fig. 3. Schematic of top blown converter. a) Physical Domain b) Numerical Domain.

Table 1. Densities of the different phases and diffusion coefficients of species in the different phases.

\begin{tabular}{cccc}
\hline & Gas & Steel & Slag \\
\hline$\rho\left[\mathrm{kg} / \mathrm{m}^{3}\right]$ & 1.225 & 7000 & 3000 \\
\hline $\mathrm{D}_{0}\left[\mathrm{~m}^{2} / \mathrm{s}\right]$ & $10^{-4}$ & $10^{-9}$ & $10^{-9}$ \\
\hline
\end{tabular}

Table 2. Initial concentrations.

\begin{tabular}{ccccc}
\hline Gas & $\mathrm{O}_{2}$ & $\mathrm{CO}$ & $\mathrm{CO}_{2}$ & $\mathrm{~N}_{2}$ \\
\hline Mass\% & 100 & 0 & 0 & 0 \\
Steel & $\mathrm{C}$ & $\mathrm{Si}$ & $\mathrm{O}$ & $\mathrm{N}$ \\
\hline Mass\% & 3.07 & 0.5 & $5 \cdot 10^{-3}$ & 0 \\
& & & & \\
Slag & $\mathrm{FeO}$ & $\mathrm{SiO}_{2}$ & & \\
\hline Mass\% & - & - & & \\
\hline
\end{tabular}

added, for instance conservation of turbulence kinetic energy, $k$, and turbulence energy dissipation, $\varepsilon$, as prescribed in the standard $k-\varepsilon$ model. ${ }^{18)}$ The following form is used for transport of any property $\phi$ :

$$
\frac{\partial}{\partial t}(\rho \phi)+\operatorname{div}(\rho \phi \mathbf{u})=\operatorname{div}(\Gamma \operatorname{grad} \phi)+S_{\phi}
$$

where $\rho$ is the density, $\mathbf{u}$ is the mean velocity vector, when using a turbulence model based on Reynolds Averaging, $\Gamma$ is the diffusion coefficient and $S_{\phi}$ is the source term, as can be seen in Table 3. Equation (1) and Table 3 describes the 
Table 3. Conservation equations.

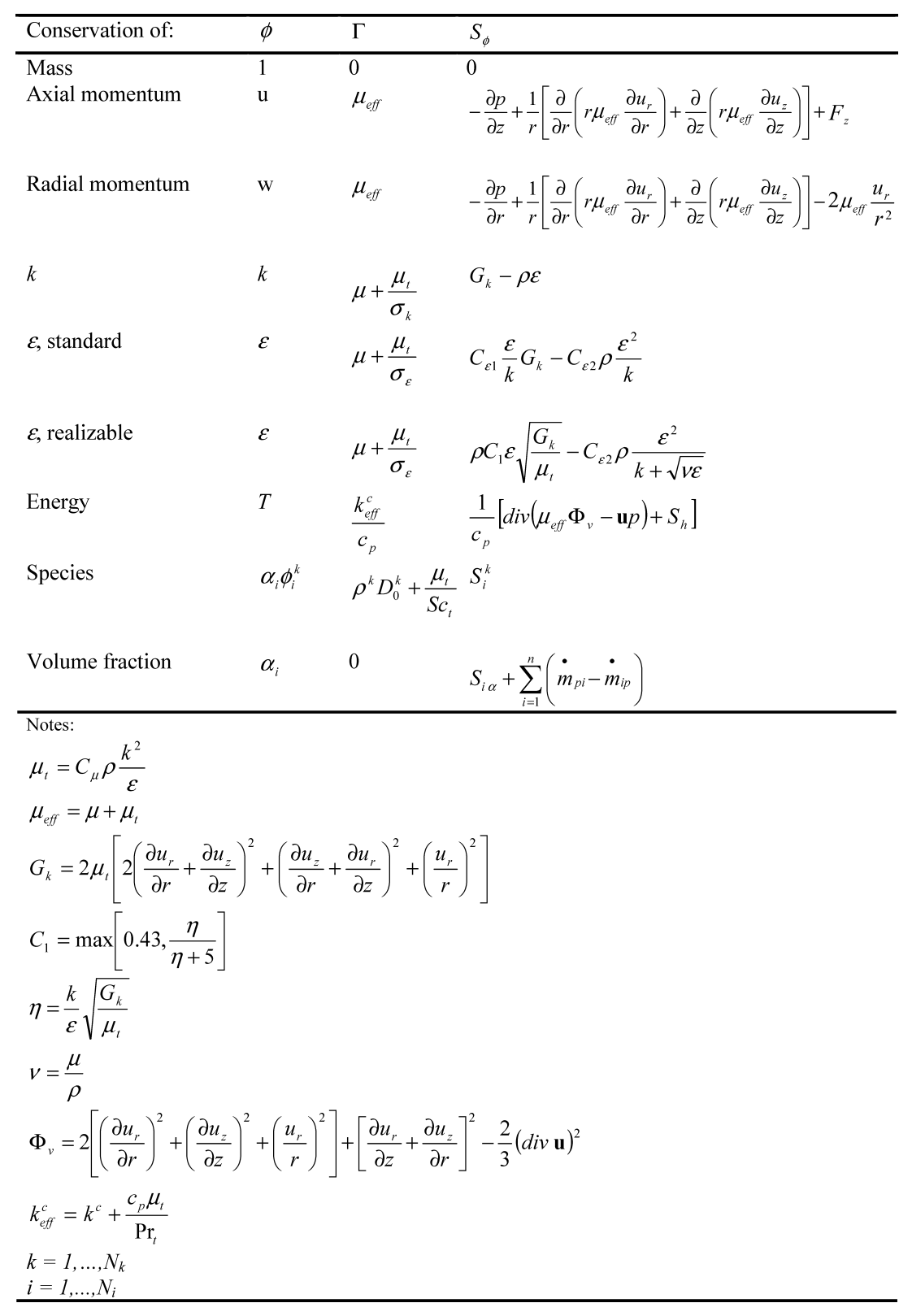

transport of; mass, momentum, turbulence kinetic energy, turbulence energy dissipation, energy, species and volume fraction.

\subsection{Thermo-Calc}

In order to obtain an accurate description of the thermodynamics the software Thermo-Calc ${ }^{21)}$ is used. This is a general software package for multi-component phase equilibrium calculations. It uses a technique that allows for a very flexible setting of conditions for the equilibrium state thus being suitable for use with process simulations.

The method of solution is the following. First, the mass and heat content in each phase is calculated separately. Then, the total mass and heat content is summed up. The system is thereafter equilibrated. Finally, the program calculates the temperature, new compositions and amounts of the phases.

To communicate with the thermodynamic software an application programming interface $\mathrm{TQ}^{21)}$ is used. This interface is one of the interfaces available within the Thermo-
Calc software package ${ }^{21)}$ and makes it possible to generalize the implementation of different system (e.g. the components and elements that the system consists of) without changing the code.

\subsection{Coupling and Assumptions}

The aim with the coupling of the two softwares, the CFD-package and the Thermo-Calc database software, is to create a general numerical model for metallurgical systems including chemical reactions. In the following text the coupling will be described. The major assumption is that local equilibrium can be reached in each computational cell during the course of each time step. The software interface between the CFD-package and the thermodynamic databases is coded in C and FORTRAN, respectively.

\subsection{Multiphase Considerations}

All bulk phases have been modeled as incompressible; having uniform density, see Table 1 . With a refinement of the model it should be possible to use an ideal gas law as- 
sumption for the gas phase and some temperature and composition dependent density model for the steel and the slag phases. To briefly explain some specifics of the functionality assume that one mole of oxygen reacts with carbon in the melt to form 2 mole of carbon monoxide. In the computational cell under consideration there will be an expansion of the gas phase to roughly twice the original volume. This in turn will most likely mean that the gas expands outside the computational cell. When coupled with CFD, the expansion will occur in the following time step, as the extra gas mass is added to the cell as source term. After a computational cell has reached equilibrium it will also have a specific temperature-the equilibrium temperature.

Assumptions:

a) Thermodynamic equilibrium can be reached in each cell during any time step.

b) The densities of gas/steel/slag are constant in time and space.

c) Equilibrium needs only to be calculated in cells containing at least two phases.

A schematic of the coupling and the solution procedure can be seen in Fig. 4.

Using the notation in Fig. 4, the outlined coupled solution procedure can be described as

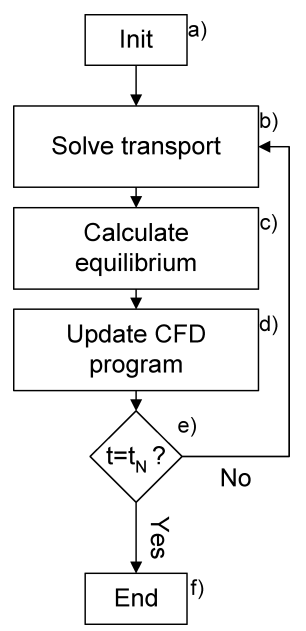

Fig. 4. Solution procedure using CFD coupled to thermodynamics. a) The model is initialized using suitable starting values for species, temperature, velocities etc.

b) Transport equations are solved using Eq. (1) with Table 3.

c) If the amount of each phase is larger than VOF_min (a preset number corresponding to the least volume to cause a call to Thermo-Calc), Thermo-Calc is called to calculate a thermodynamic equilibrium.

d) The new species distribution and temperature in the cell are set directly. The mass transfer between the phases is stored and used in the subsequent time step.

e) A check is done to determine if a convergence criterion has been reached, such as a predetermined time or a steady state.

f) If convergence has been reached the program terminates. Otherwise it resumes at b) using the current variables.

\section{Results}

\subsection{Fundamental Top Blown Converter}

In Fig. 5 vector plot showing the gas jet, as it impinges on the steel bath, is shown. It is seen that the jet looses its axial momentum as it hits the bath surface. The low flow rate from the lance gives a relatively small penetration in the steel bath.

Figure 6 illustrates the flow field in the steel bath caused by the impinging oxygen jet. The highest velocities are present where the jet hits the bath and in the surface area. The fluid moves from the penetration zone towards the wall and then down into the bath. A large re-circulation loop is formed in the center of the bath (i.e. between the axis and the wall) and several small re-circulation loops are formed close to the surface. It should be noted that the velocity magnitude in the larger loop is very small. This is attributed to the low flow rate from the top lance. Higher flow rates render larger penetration and a stronger bath circulation.

Figure 7 illustrates the carbon concentration in the bath at times 1, 2, 3 and $5 \mathrm{~s}$. First of all the plotting limits should be noted, where it can be seen that the range of the plot is quite narrow. This is intentional in order to make the small concentration differences visible over the range of plotting

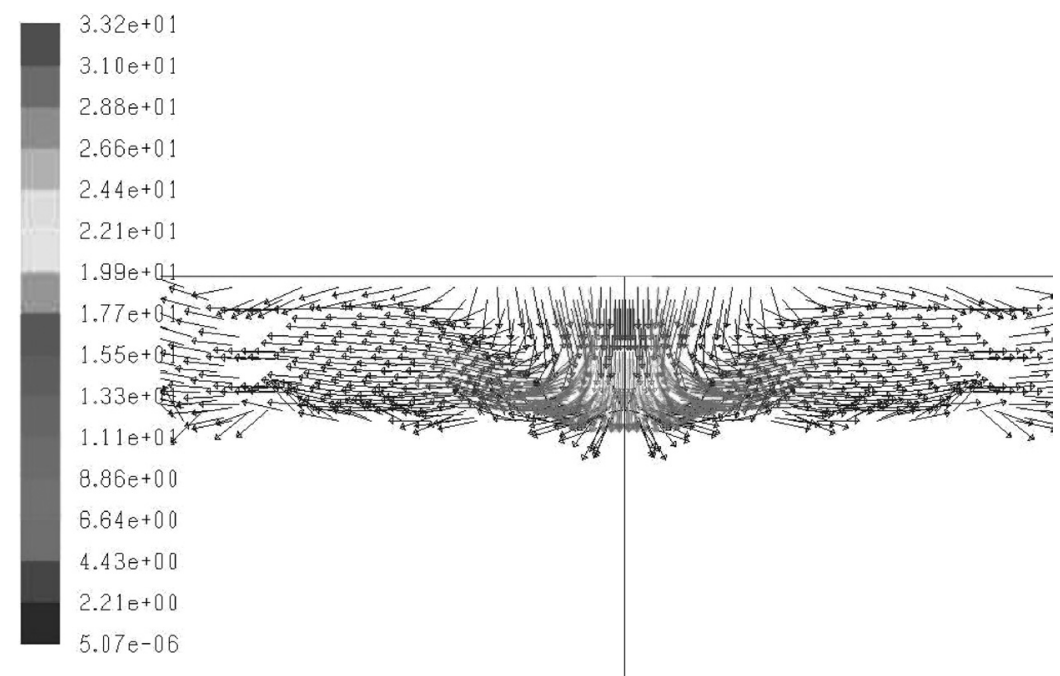

Fig. 5. Velocity vector plot in gas. Vectors have a fixed length; instead they are colored by velocity magnitude (m/s). 
colors used. It can be seen from Fig. 7(a) that a carbon concentration gradient exists in a small region close to the free surface area as well as in a larger region to the right of the penetration zone. When examining Figs. 7(a)-7(d) it becomes evident that the larger region moves towards the wall of the converter and that it also becomes larger with time. The carbon concentration in the moving region slowly de-

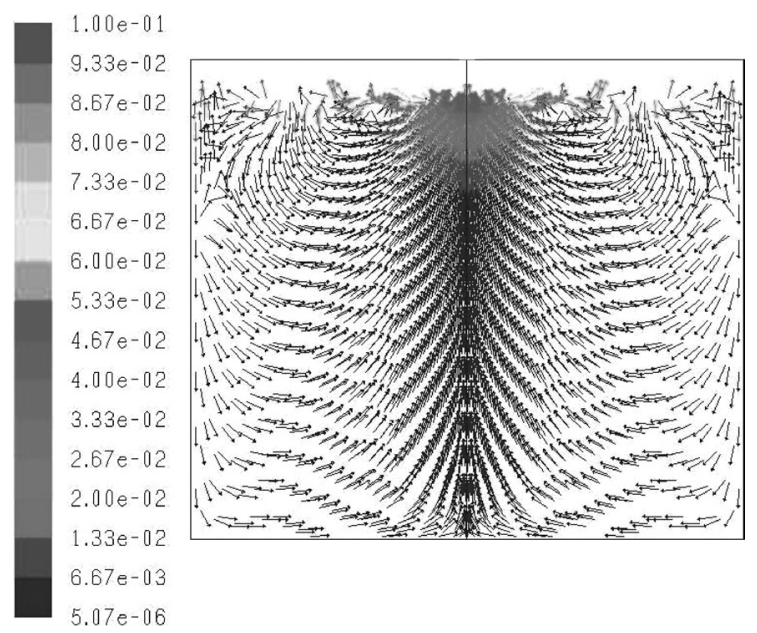

Fig. 6. Velocity vector plot in the steel. Vectors have a fixed length; instead they are colored by velocity magnitude $(\mathrm{m} / \mathrm{s})$.
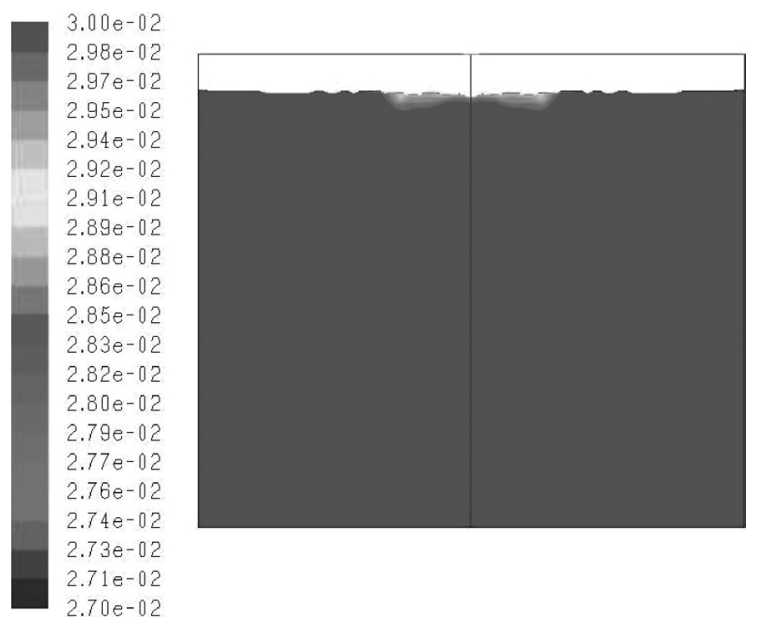

Fig. 7a. Mass fraction of carbon in steel. $1 \mathrm{~s}$ simulation time.

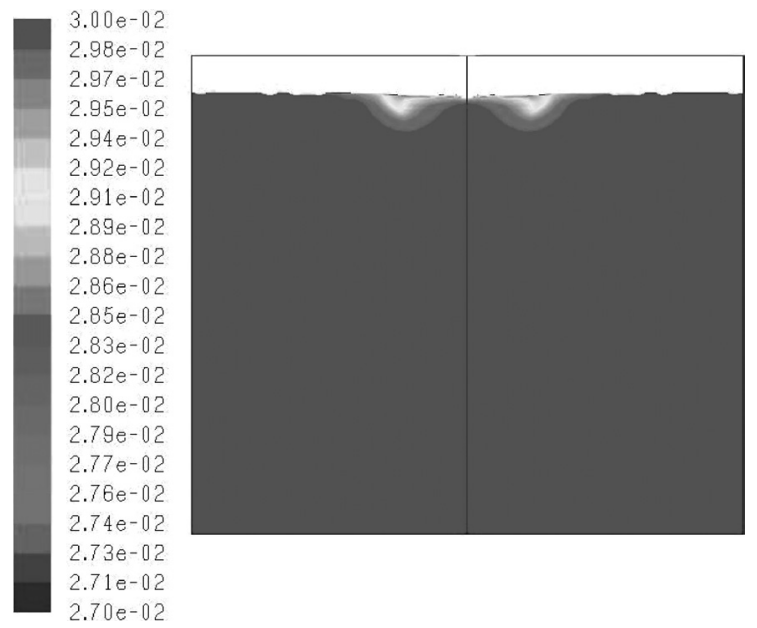

Fig. 7b. Mass fraction of carbon in steel. $2 \mathrm{~s}$ simulation time. creases between Figs. 7(a)-7(d). It seems that the decarburized steel is transported along the surface (see Fig. 6) and subsequently dragged down into the bath due to the recirculation pattern present in the flow and because of turbulent mixing. The depth of the decarburized steel is only a few millimeters in the penetration zone; however the really large gradients appear in an even thinner region close to the free surface. Gradually, as the flow field develops, the recirculation zone moves towards the wall.

Figure 8 illustrates the $\mathrm{CO}$ gas concentration present in the gas phase. The region where the jet impinges on the steel surface is almost exclusively filled with $\mathrm{O}_{2}$ so no $\mathrm{CO}$ is present there, except for a thin layer right next to the bath surface. The CO gas amount then becomes gradually more pronounced as the distance to the wall decreases.

\section{Discussion}

From the simulation it was found that no slag was created during the first $20 \mathrm{~s}$ of the blow. The reason for this is likely connected to the initially high carbon concentration as well as the low silicon concentration in the metal bath (see Table 2) together with the conditions associated with the simulated laboratory experiment, i.e. a low oxygen flow rate. Also, in the present simulation the drop in carbon concentration in the bulk was very small. This is mainly attrib-

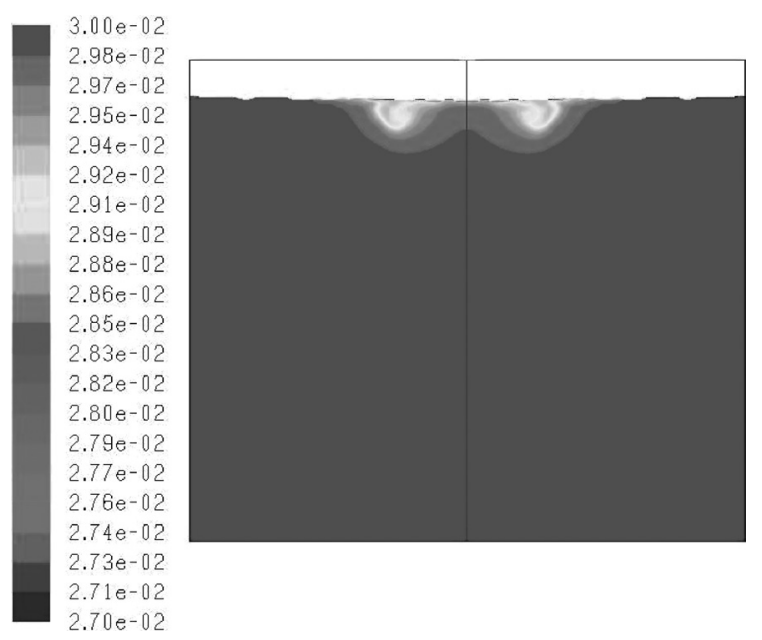

Fig. 7c. Mass fraction of carbon in steel. $3 \mathrm{~s}$ simulation time.

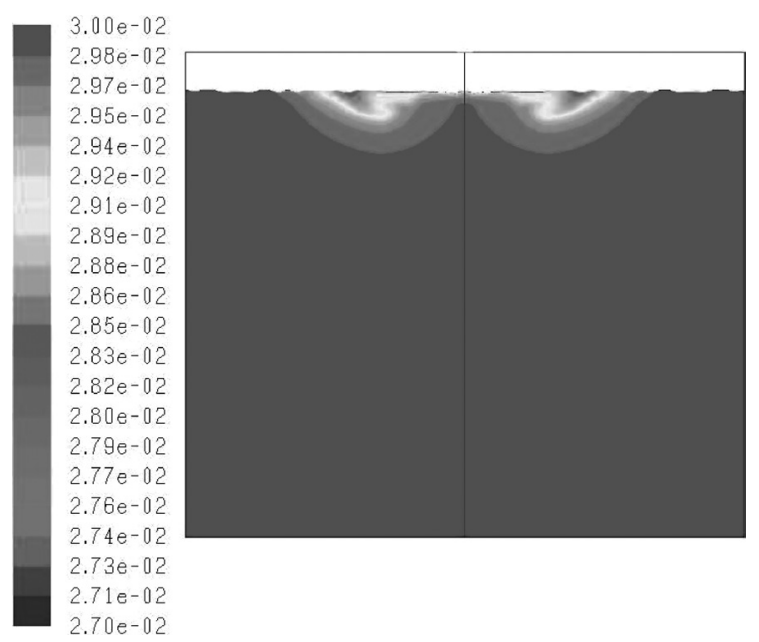

Fig. 7d. Mass fraction of carbon in steel. $5 \mathrm{~s}$ simulation time. 


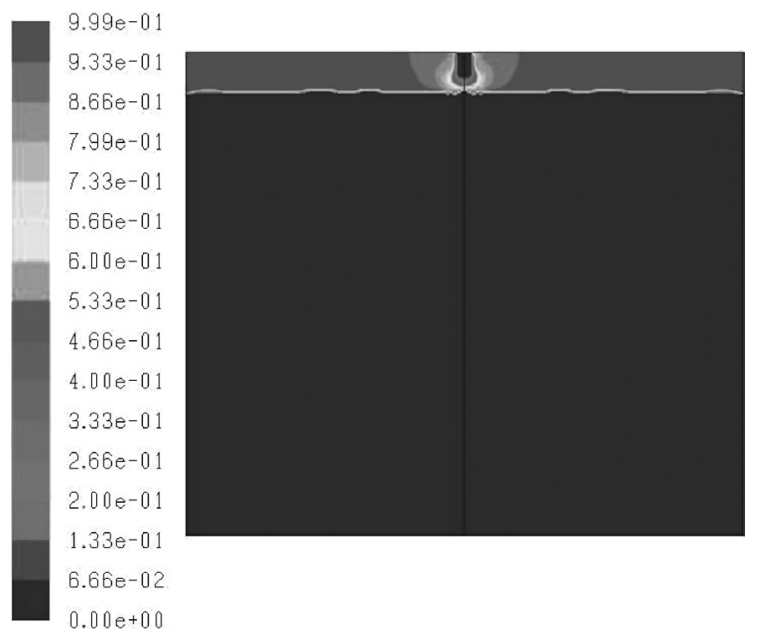

Fig. 8. Mass fraction of $\mathrm{CO}$ in the gas phase. $5 \mathrm{~s}$ simulation time.

uted to the short simulation time in combination with the flow rate of oxygen from the top lance. It was possible to do a macroscopic balance of the entire system with respect to carbon concentration in the steel and then extrapolate the current data from $5 \mathrm{~s}$ to $15 \mathrm{~min}$. This was done in two steps. At first the decarburization rate was calculated based on the results obtained at $5 \mathrm{~s}$ :

$$
\frac{d\left(\tilde{f}_{\mathrm{C}}\right)}{d t}=\frac{\Delta \tilde{f}_{\mathrm{C}}}{\Delta t}
$$

where $\tilde{f}_{\mathrm{C}}$ is the mass-weighted fraction carbon in the steel calculated as:

$$
\tilde{f}_{\mathrm{C}}=\frac{\int f_{\mathrm{C}} \rho d V}{\int \rho d V}=\frac{\sum_{i=1}^{n} f_{\mathrm{C}, i} \rho_{i}\left|V_{i}\right|}{\sum_{i=1}^{n} \rho_{i}\left|V_{i}\right|}
$$

where $f_{\mathrm{C}, i}$ and $\rho_{i}$ is the mass fraction carbon and density in cell $i$ respectively and $V_{i}$ is the volume of cell $i$. When employing a linear extrapolation of $\tilde{f}_{\mathrm{C}}$ from $5 \mathrm{~s}$ to $15 \mathrm{~min}$ the carbon concentration in the steel would drop from 3 to 2.2 mass $\%$. This can be compared to the experimental results of Nordquist et al. where the carbon concentration dropped from about 3.07 to about 2.2 mass $\%$ in a linear fashion. ${ }^{22)}$ It seems that in the current simple system a linear extrapolation is valid since the decarburization rate stays almost constant over the time investigated. ${ }^{22)}$ It should be noted that although Eq. (3) gives the mass-weighted average of the mass fraction carbon in the bulk this might not be the case when taking experimental measurements unless the mixing is ideal. As simulations show (Figs. 7(a)-7(d) there is a concentration gradient in the steel indicating that the position of experimental sampling could influence the experimental results.

When dissolved carbon reacts with oxygen to form carbon monoxide the following equation can be written:

$$
2 \underline{\mathrm{C}}+\mathrm{O}_{2}=2 \mathrm{CO}(\mathrm{g})
$$

The equilibrium constant of Eq. (4) is:
Cell Péclet Number

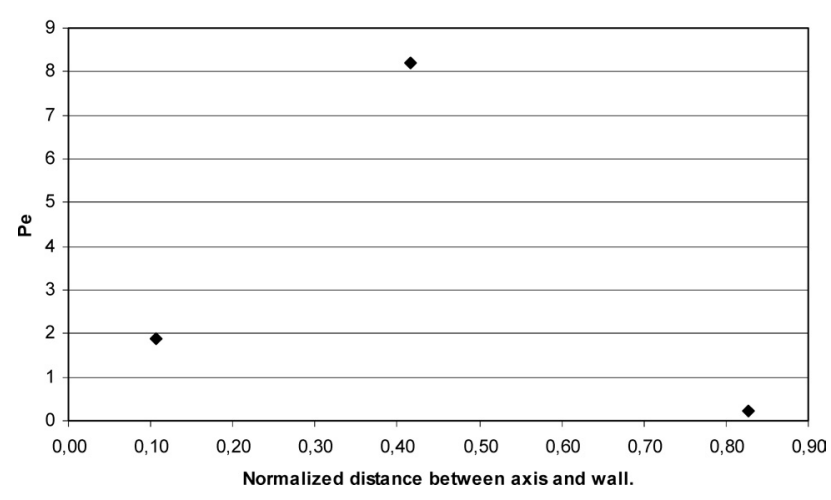

Fig. 9. Cell Péclet number as a function of normalized distance between axis and wall at $5 \mathrm{~s}$ simulation time.

$$
K=\frac{P_{\mathrm{CO}}^{2}}{a_{\underline{\mathrm{C}}}^{2} \cdot P_{\mathrm{O}_{2}}}
$$

where $K, a_{\mathrm{C}}, P_{\mathrm{CO}}$ and $P_{\mathrm{O}_{2}}$ are the equilibrium constant, the activity of dissolved carbon in steel, the partial pressure of $\mathrm{CO}$ and the partial pressure of $\mathrm{O}_{2}$ respectively. Equation (10) can be rewritten as:

$$
a_{\underline{\mathrm{C}}}=\sqrt{\frac{P_{\mathrm{CO}}^{2}}{K \cdot P_{\mathrm{O}_{2}}}}
$$

From Eq. (6) it can be concluded that a high partial pressure of $\mathrm{CO}$ will lead to a high carbon activity in the steel. With the above reasoning Fig. 8 indicates that the decarburization far from the penetration zone would be slow or none existing due to the high partial pressure of $\mathrm{CO}$ gas. This would be true for both decarburization taking place at the free surface and also decarburization in droplets being thrown into that area.

The Péclet number can be used to give an indication of the relative strength of convection compared to diffusion. If the Péclet number is high then the convection is dominating the flow and if it is low diffusion dominates the flow. The Péclet number is defined as:

$$
P e=\frac{V L}{D_{\mathrm{t}}}
$$

where $V$ is the velocity, $L$ is the characteristic length and $D_{\mathrm{t}}$ is the turbulent mass diffusivity. In Fig. 9 a plot of the Péclet number for some surface cells located at different radial positions can be seen. The axial height of the cell was used as the characteristic length and the mass diffusivity value was taken using values from Table 1 . It is seen that the Péclet number is not very high for the three points investigated in Fig. 9. This means that the turbulent diffusion of mass is relatively strong in the system and should not be neglected.

\section{Conclusions}

A new modeling approach has been presented where a CFD software has been coupled to a thermodynamic database (Thermo-Calc) using custom subroutines to obtain dy- 
namic simulations of metallurgical process phenomena. Reactions between gas-steel, gas-slag, steel-slag and gassteel-slag have been considered in a fundamental model of a top-blown converter. The overall conclusion is that it is possible to make a dynamic coupling of the Thermo-Calc databases and the CFD software to make dynamic simulations of metallurgical processes such as a top-blown converter.

Specific conclusions from the top blown converter simulations include:

(1) Turbulent diffusion of species can not be neglected when considering the species transport in the surface area.

(2) The large amount of CO produced during the decarburization might slow down the rate of decarburization in droplets ejected from the bath.

(3) It is possible to use extrapolation of the decarburization rate, sampled from a few seconds of simulation, to get a rough estimate of the carbon content at a later stage in the process as long as the carbon content is relatively high (compare next point).

(4) For the current system, concentrations of about 3 mass \% carbon in the steel yields no initial amount of slag. $\mathrm{FeO}$ and/or $\mathrm{SiO}_{2}$ created are close to zero i.e. only gas $\left(\mathrm{CO}+\mathrm{CO}_{2}\right)$ is created as the oxygen jet hits the steel bath.

To find out the combination of concentrations, flow rates and temperatures that renders the most efficient decarburization, a future parametric study would be of interest.

\section{Acknowledgements}

This work was financially supported by the Swedish Foundation for Strategic Research (SSF) and the Swedish steel industry through the Centre for Computational Thermodynamics (CCT).

\section{Nomenclature}

$D_{0}$ : Molecular mass diffusivity $\left[\mathrm{m}^{2} \mathrm{~s}^{-1}\right]$

$D_{\mathrm{t}}$ : Turbulent mass diffusivity $\left[\mathrm{m}^{2} \mathrm{~s}^{-1}\right]$

$\varepsilon$ : Turbulence dissipation $\left[\mathrm{m}^{2} \mathrm{~s}^{-3}\right]$

$f_{\mathrm{C}}$ : Mass fraction carbon in steel

$\tilde{f}_{\mathrm{C}}$ : Mass-weighted average mass fraction carbon in steel

$\mathrm{g}$ : Gravitational acceleration $\left[\mathrm{m} \mathrm{s}^{-2}\right]$

$k$ : Turbulence kinetic energy $\left[\mathrm{m}^{2} \mathrm{~s}^{-2}\right]$

$k_{0}^{i}$ : Diffusion coefficient of species $i\left[\mathrm{~kg} \mathrm{~m}^{-1} \mathrm{~s}^{-1}\right]$

$k_{\text {eff }}^{c}$ : Effective thermal conductivity $\left[\mathrm{W} \mathrm{m}^{-1} \mathrm{~K}^{-1}\right]$

$\mu$ : Molecular viscosity $\left[\mathrm{kg} \mathrm{m}^{-1} \mathrm{~s}^{-1}\right]$

$v$ : Kinematic viscosity $\left[\mathrm{m}^{2} \mathrm{~s}^{-1}\right]$ $\dot{m}: \quad$ Mass rate of change $\left[\mathrm{kg} \mathrm{s}^{-1}\right]$

$N_{i}$ : Number of phases

$N_{k}$ : Number of scalars in the phase $k$

$\phi$ : General transported property

$\phi_{i}{ }^{k}$ : Scalar $k$ in phase $i$

$P:$ Pressure $\left[\mathrm{N} \mathrm{m}^{-2}\right]$

$P e$ : Cell Peclét number

$\mathrm{Pr}_{\mathrm{t}}$ : Turbulent Prandtl number

$\rho:$ Density $\left[\mathrm{kg} \mathrm{m}^{-3}\right]$

$S_{\phi}$ : Source term for general property $\phi$

$S c_{\mathrm{t}}$ : Turbulent Scmidt number (here assumed $=0.7$ )

$u_{r}$ : Radial velocity component $\left[\mathrm{m} \mathrm{s}^{-1}\right]$

$u_{z}$ : Axial velocity component $\left[\mathrm{m} \mathrm{s}^{-1}\right]$

$\Gamma$ : Diffusion coefficient for general property $\phi$

\section{REFERENCES}

1) E. T. Turkdogan: Chem. Eng. Sci., 21 (1966), 1133.

2) N. A. Molloy: J. Iron Steel Inst., (1970), Oct., 943.

3) T. Kumagai and M. Iguchi: ISIJ Int., 41 (2001), S52.

4) A. Nordquist, N. Kumbhat, L. Jonsson and P. Jönsson: Steel Res. Int., 2 (2006), 82.

5) B. Banks and D. V. Chandrasekhara: J. Fluid Mechanics, 15 (1963), 13.

6) A. Chatterjee and A. V. Bradshaw: The Interaction Between Gas Jets and Liquids, Including Molten Metals, 314.

7) M. Ersson, A. Tilliander, M. Iguchi, L. Jonsson and P. Jönsson: ISIJ int., 46 (2006), No. 8, 1137.

8) J. Szekely and S. Asai: Metall. Trans, 5 (1974), 464.

9) A. Nguyen and G. Evans: 3rd Int. Conf. on CFD in the Minerals and Process Industries CSIRO, Melbourne, Australia, (2003), 71.

10) J.-Y. Zhang, S.-S. Du, S.-K. Wei: Ironmaking Steelmaking, 12 (1985), 249

11) H.-J. Odenthal, U. Falkenreck and J. Schlüter: European Conf. on Computational Fluid Dynamics, the Netherlands, (2006).

12) D. Nakazono, K.-I. Abe, M. Nishida and K. Kurita: ISIJ Int., 44 (2004), 91.

13) M. Ersson, A. Tilliander, and P. Jönsson: Proc. Sohn Int. Symp Advanced Processing of Metals and Materials, ed. by F. Kongoli and R. G. Reddy, TMS, San diego, USA, Aug 27-31, (2006), p. 271.

14) L. Jonsson, D. Sichen and P. Jönsson: ISIJ Int., 38 (1998), 260.

15) L. Jonsson: PhD Thesis, Dept. of Metallurgy, KTH, Sweden, (1998).

16) L. Jonsson, P. Jönsson, S. Seetharaman and D. Sichen: Proc. of 6th Japan-Nordic Countries Steel Symp., ISIJ, Tokyo, (2000), 77.

17) C. W. Hirt and B. D. Nichols: Comput. Physics, 39 (1981), 201.

18) B. E. Launder and D. B. Spalding: Comp. Meth. Appl. Mech. Eng., 3 (1974), 269.

19) Fluent User's Manual, (2007).

20) T.-H. Shih, W. W. Liou, A. Shabbir, Z. Yang and J. Zhu: Computers Fluids, 24 (1995), 227.

21) J.-O. Andersson, T. Helander, L. Höglund, P. Shi, and B. Sundman: Calphad, 26 (2002), 273.

22) A. Nordquist, A. Tilliander and P. Jönsson: Proc. 5th European Oxygen Steelmaking conf., Aachen, Germany, (2006), 519. 